\title{
Orofacial pain management: current perspectives
}

\author{
This article was published in the following Dove Press journal: \\ Journal of Pain Research \\ 21 February 2014 \\ Number of times this article has been viewed
}

\author{
Marcela Romero-Reyes \\ James M Uyanik \\ Orofacial and Head Pain Service, \\ Department of Oral and Maxillofacial \\ Pathology Radiology and Medicine, \\ New York University College of \\ Dentistry, New York, NY, USA
}

\begin{abstract}
Some of the most prevalent and debilitating pain conditions arise from the structures innervated by the trigeminal system (head, face, masticatory musculature, temporomandibular joint and associated structures). Orofacial pain (OFP) can arise from different regions and etiologies. Temporomandibular disorders (TMD) are the most prevalent orofacial pain conditions for which patients seek treatment. Temporomandibular disorders include a number of clinical problems that involve the masticatory musculature, the temporomandibular joint (TMJ) or both. Trigeminal neuropathic pain conditions can arise from injury secondary to dental procedures, infection, neoplasias, or disease or dysfunction of the peripheral and/or central nervous system. Neurovascular disorders, such as primary headaches, can present as chronic orofacial pain, such as in the case of facial migraine, where the pain is localized in the second and third division of the trigeminal nerve. Together, these disorders of the trigeminal system impact the quality of life of the sufferer dramatically. A multidisciplinary pain management approach should be considered for the optimal treatment of orofacial pain disorders including both non-pharmacological and pharmacological modalities.
\end{abstract}

Keywords: pain, orofacial, neuropathic, TMD, trigeminal, headache

\section{Orofacial pain disorders}

Orofacial pain disorders are highly prevalent and debilitating conditions involving the head, face, and neck. These conditions represent a challenge to the clinician since the orofacial region is complex and therefore, pain can arise from many sources. The clinician needs to have solid knowledge of the pain conditions that arise from these structures for proper diagnosis and a multidisciplinary approach of management is strongly recommended.

The orofacial pain classification as outlined by Okeson $^{1,2}$ is divided into physical (Axis 1) and psychological (Axis 2) conditions. Physical conditions comprise temporomandibular disorders (TMD), which include disorders of the temporomandibular joint (TMJ) and disorders of the musculoskeletal structures (eg, masticatory muscles and cervical spine); neuropathic pains, which include episodic (eg, trigeminal neuralgia $[\mathrm{TN}]$ ) and continuous (eg, peripheral/centralized mediated) pains and neurovascular disorders (eg, migraine). Psychological conditions include mood and anxiety disorders. This review focuses on the current perspectives in orofacial pain management, and only TMD, neuropathic pains, and headaches will be discussed. For a more comprehensive discussion about pathophysiology and diagnosis of the disorders depicted in this classification and other painful disorders arising from the head, face, and neck, other texts should be reviewed.
Correspondence: Marcela Romero-Reyes Department of Oral and Maxillofacial Pathology, Radiology and Medicine, New York University College of Dentistry, 345 E, 24rd St, New York, NY 10010, USA

Emailmrr7@nyu.edu 


\section{TMD}

"TMD" defines a number of clinical problems that involve the masticatory musculature, the TMJ, and associated structures. ${ }^{3}$ TMD is considered to be a subclassification of musculoskeletal disorders ${ }^{1}$ and is the most prevalent condition for which patients seek treatment. ${ }^{4,5}$ The careful evaluation of these facial structures in conjunction with clinical symptoms is crucial in forming a proper differential diagnosis. The patient may present with jaw ache, earache, toothache, facial pain, and/or headache; however, the complaint may be as benign as general facial fullness or pressure. Treatment planning depend on various factors, including the chief complaint, medical history, presenting symptoms, examination, and diagnosis. In the past, TMD cases have sometimes been considered to be difficult to diagnose and problematic to treat; however, thanks to ongoing research in orofacial pain and pain management, clinicians are able to use a more standardized classification and better diagnostic and therapeutic methods to offer patients a wide range of treatment modalities with higher success rates.

\section{Natural history and epidemiology of TMD}

Most epidemiological studies clearly demonstrate that TMD symptoms are more commonly seen in women than in men, ${ }^{1}$ and that many symptoms seem to arise in adolescence or the early twenties and may continue intermittently, well into middle age; however, TMD symptomatology does get better with time, supporting a conservative management approach. In a study by Solberg et al, ${ }^{6} 76 \%$ of subjects aged $18-25$ years had one or more signs associated with TMD and 26\% had at least one symptom associated with TMD. Of this group, only $10 \%$ had symptoms that were considered by the subjects to be severe enough to seek treatment. Rasmussen ${ }^{7}$ found that most cases of a clicking TMJ did not evolve into an open or closed locking state. Rasmussen noted that, in the natural progression of internal derangement, acute TMD symptoms lasted a mean of 5.5 years and that, although joint noises generally did not disappear, most painful and disabling symptoms subsided in time. Similar results were shown by Könönen et al, who followed 128 Finnish adults over 9 years, in whom the incidence of clicking increased with age. ${ }^{8}$ None of the patients, however, developed locking. In a more recent study, the presence of degenerative joint disorders was found to be the discriminating factor in two different age subgroups: patients with a mean age range of 52 years presented a prevalence of crepitus, while patients with a mean age range of 38 years did not. ${ }^{9}$

\section{Disorders of the TMJ}

Disorders of the TMJ are a result of a disc-condyle incoordination that influences the TMJ biomechanics. These disorders comprise the disc interference disorders or internal derangements, such as disc displacements with and without reduction, that can be asymptomatic or symptomatic due to inflammation (eg, capsulitis/synovitis). Disc displacements with reduction may present as a painful or non-painful click. Disc displacements without reduction may present with a painful limitation at opening. Retrodiscitis and TMJ subluxation may present symptomatology when the pain is a result of inflammation arising from the retrodiscal tissues or capsulitis or synovitis processes. Osteoarthritic changes can originate in the TMJ articular surfaces and, when they are influenced by a systemic disease, can become aggressive and progressive, such as in the case of polyarthritis.

\section{Muscular disorders}

Myalgia usually presents as a dull aching pain due to muscle injury or strain. It is commonly seen in acute forms, though, with continued muscle tension, can present for longer periods of time. Treatment may include, rest, hot or cold compresses, stretching exercises, and muscle relaxants. Myofascial pain (MFP) also presents as a dull, continuous aching pain that varies in intensity. MFP produces pain upon palpation that is local and may refer to other sites, as mapped out by Simons et al. ${ }^{10}$ MFP tends to be seen in muscle pain conditions of a more chronic nature, in which the tension is unremitting. Trigger points can often be seen in MFP and may be localized to a taut band of muscle. In addition, trigger points are associated with decreased muscle length and, when stimulated, can result in a local twitch response. ${ }^{11}$ Palpation of the trigger points should duplicate the patient's pain complaint, thus confirming diagnosis. Blocking the source of the pain (ie, masseter muscle) by using a vapocoolant spray or local anesthetic injection can also provide a definitive diagnosis.

Myositis is a localized transient swelling involving the muscle and facial tissues. ${ }^{12}$ There tends to be increased pain with mandibular movement and localized tenderness, usually following injury or infection.

\section{Patient evaluation}

TMD assessment should include a general examination of the head and neck, a detailed examination of the masticatory muscles, an evaluation of the TMJs, an evaluation of mandibular range of motion (ROM), and a detailed intraoral examination. ${ }^{13}$ 


\section{Evaluation of the TMJs and mandibular ROM}

The evaluation of the TMJs includes examination for any signs of dysfunction or pain symptomatology. Fingertips are placed over the lateral and posterior aspects of the TMJs applying light but steady force and performed when the mandible is at rest/closed position and opening. Symptomatology reported in response to force applied to the lateral aspect of TMJs may be a sign of capsulitis/synovitis. Symptomatology reported in response of force applied to the posterior aspect of the condyle may be a sign of retrodiscitis or posterior capsulitis.

The clinician should be aware of joint sounds, which could present as clicks, pops, or crepitus. ${ }^{1}$ These sounds are evaluated with the help of a stethoscope placed in the TMJ area or sometimes perceived during palpation. Clicks and pops are commonly related to disc displacements with reduction and crepitation is commonly associated with osteoarthritic changes in the articular surfaces of the TMJ. ${ }^{14}$ Imaging of the TMJ may also be useful during examination. Moreover, it is very important to identify any TMJ restrictions. The clinician should view the patient's opening and closing patterns to note any mandibular deviations. The evaluation of mandibular ROM consists of measuring comfort opening, active opening, passive opening, protrusion, and left and right lateral excursions with a millimeter ruler while noting the severity and location of pain with jaw movement. This can be particularly helpful in differentiating between joint and muscle pain. Comfort opening is determined by the patient opening as wide as possible without any pain, active opening is determined by the patient opening as wide as possible with pain, and passive opening is determined by the clinician gently stretching the patient presumably past active opening while noting a soft or hard end feel. A reasonably normal interincisal distance is approximately $40 \mathrm{~mm}$, or the width of three of the patient's fingers as a crude measure. Usually, with proper questioning, the patient will reliably reveal any recent limitations in ROM. The occurrence of TMJ clicking, crepitus, or jaw opening interferences with or without pain should also be noted at the initial examination. These baseline findings will aid in establishing the differential diagnosis and treatment options, as well as providing a comparison for future change in TMD symptoms.

\section{Evaluation of the muscles of mastication}

The muscles of mastication should be palpated bilaterally for firmness and tenderness, utilizing approximately $2-3 \mathrm{lbs}$ of pressure ${ }^{15}$ or the amount of pressure needed to cause blanching of the fingernail. Upon muscular palpation, the patient should be asked to report the severity of the tenderness, pain referral to multiple sites or single-site pain localization, and replication of the chief complaint upon palpation. It may be pertinent to ask the patient about their use of analgesics prior to palpation in order to account for reduced symptoms upon examination.

\section{Management of TMD}

Most of the time, patients will visit the clinician when pain and dysfunction, such as limitation of opening, episodes of joint locking (open lock/TMJ subluxation), pain with mandibular function (chewing), facial pain, or headache are present.

The treatment goals for TMD are decreasing pain, restoring normal ROM, and restoring normal masticatory and jaw function. Many TMDs can be cyclical and self-limiting, with periods of complete remission of symptoms.

In the case of disc-condyle incoordinations, studies suggest that for some patients even though they may be progressive (for example, a disc displacement with reduction may progress to a disc displacement without reduction), they are self limiting, suggesting an adaptation of the condition and with no significant disability. ${ }^{1,76,17}$ It is very important to emphasize that patients have no recurrence of symptoms with the use of conservative, reversible treatments, ${ }^{16,18}$ thus conservative treatment is the modality that needs to be used at all times. Initial treatment should therefore stress a conservative and reversible approach. Primary treatment options include home care (self-care program), medical care (non-surgical care), and surgical care.

\section{Patient education: home care program}

Home care should generally be the initial approach, at least as part of a more extensive treatment plan. The use of a home care program has proved to be effective in the management of TMD. It has been shown that patients have reported feeling less pain immediately after their initial patient education/counseling visit, perhaps as a consequence of an immediate reduction in stress/ tension-related parafunctional activity. ${ }^{1,19}$ Patient education is a crucial aspect of home care and is one of the most subtle and underappreciated, yet effective, treatments for TMD. Therefore, informing and reassuring the patient regarding their condition and presenting symptoms may alleviate a great deal of anxiety and improve treatment outcomes.

A successful home care program consists of resting the masticatory muscles by limiting jaw movements, parafunctional habit modification, emphasizing a soft diet, and moist heat and/or ice therapy. ${ }^{20}$ Muscle rest may involve limited jaw activity (eg, reduced talking, chewing, yawning) 
for the treatment duration, and perhaps as a preventive measure, even after symptoms have resolved. Patients with disc displacement without reduction should be instructed to avoid any forceful attempt to open the mouth wider when the condition is acute and have explained to them that, with the care provided, the ROM will improve and return to normal. ${ }^{1}$ Restricting the mandibular movements as much as possible would facilitate healing and prevent further injury. ${ }^{20}$ This could be attained with a soft food diet, avoiding chewing gum and hard foods, and limitation of opening during yawning, as well as habit awareness, such as avoiding biting objects, clenching, or bruxing. ${ }^{1,3}$ Patients may have a diurnal (daytime) parafunctional habit (clenching, grinding, posturing) that is often not conscious, and this should be addressed to decrease sustained masticatory muscle contractions. ${ }^{21}$ Patient education and understanding of the physiological rest position (lips together, teeth apart) is imperative in reducing and eventually halting the daytime activity that contributes to the progression of TMD. If asked to pay attention to their jaw position over time, many patients will return for follow-up with the recognition that they are in fact engaging in some jaw activity that contributes to their symptoms. Additionally, suggesting habit-controlling cues may be helpful in reminding the patient throughout the day to check the position of their bite. As an example, saying the letter " $N$ " throughout the day can remind the patient to unclench or discontinue grinding their teeth. A soft diet is also crucial for muscle and TMJ pain management so that the condition is not exacerbated while treatment is provided. Finally, a trial of moist heat and/or ice therapy overlying the painful areas of the face, head, and neck can be recommended. Moist heat tends to work better for muscle pain or tension by increasing circulation and relaxing involved muscles, and ice for TMJ capsulitis by reducing inflammatory symptoms.

\section{Medical care (non-surgical)}

Physical therapy

Instructing the patient to apply moist heat or cold compresses, or alternating both modalities, has been proven to be beneficial, since it stimulates analgesia and relaxation and may improve movement. ${ }^{12,22}$

Physical therapy is beneficial in restoring the normal function of the TMJ, muscles of mastication, and cervical muscles, as well as in reducing inflammation, promoting repair, and strength. ${ }^{22-24}$ Physical therapy can be performed by an experienced physical therapist ${ }^{3}$ or can be provided by a qualified clinician who is treating the TMJ disorder. Primary goals of the physical therapy component of treatment are to stretch chronically contracted and fatigued muscles, increase ROM, and reduce muscular trigger point activity. ${ }^{25}$ A number of exercises are commonly used to treat TMJassociated muscle disorders, including N-stretch (placing the tip of the tongue on the roof of the mouth and stretching the jaw) (Figure 1); chin to chest (gently pulling the head forward, bringing the chin toward the chest); and head tilt (turning the head to one side and then tilting it posteriorly). These exercises must be done four to six times per day to be effective. In addition, the patient should use moist heat for 10-15 minutes followed by ethyl chloride spray prior to stretching the muscles. Vapocoolant spray provides a temporary anesthesia effect to the muscles so that a more intense stretch can be achieved without pain. The heat and cooling spray should be used for at least three of the six exercising sessions throughout the day. Patients can expect an even higher likelihood of treatment success if transcutaneous electrical nerve stimulation is added to a strict stretching regimen, ${ }^{26}$ and if biofeedback training is used as a cognitive behavioral procedure to teach the patient to maintain reduced muscular tension and pain..$^{21,27}$

\section{Pharmacotherapy}

Medications are an effective addition in managing the symptomatology of intracapsular disorders. ${ }^{1}$ Commonly used pharmacological agents for the treatment of TMJ disorders include analgesics, nonsteroidal anti-inflammatory drugs (NSAIDs), local anesthetics, oral and injectable corticosteroids, sodium hyaluronate injections, muscle relaxants, botulinum toxin

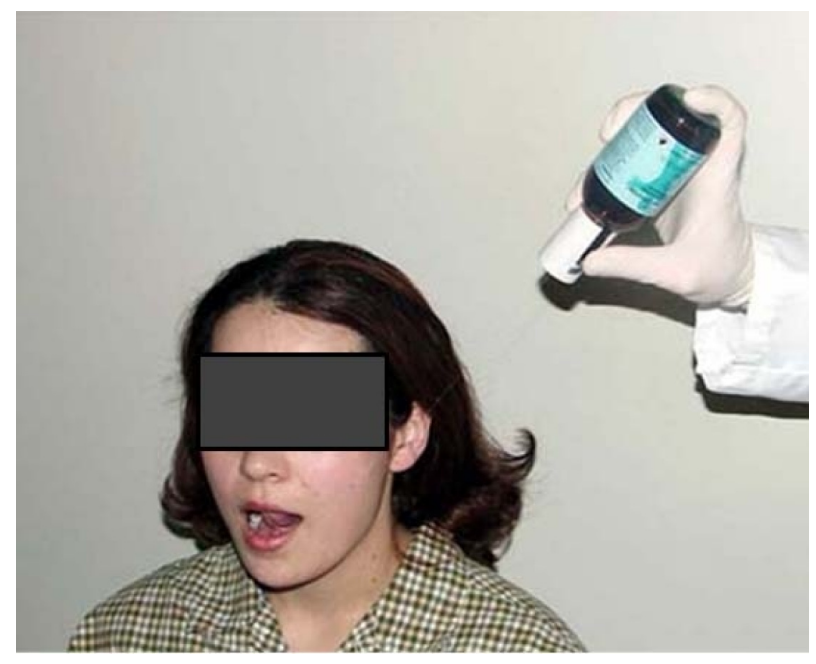

Figure I Jaw $\mathrm{N}$-stretch with vapocoolant spray.

Notes: The patient is instructed to place the tip of the tongue on the roof of the mouth just behind the frontal teeth (like saying the letter "N") and to open stretching the mandible while the spray is directed towards the face (masseter muscle region) in an upward motion. 
injections, and antidepressants. ${ }^{12,28-30}$ The analgesics and corticosteroids are indicated for acute TMD pain; the NSAIDs, local anesthetics, and muscle relaxants are used for both acute and chronic conditions; and tricyclic antidepressants are usually used more for chronic TMD pain in association with tension-type headaches. ${ }^{28,31}$ Research demonstrating the efficacy of botulinum toxin for muscular disorders related to TMD is limited, ${ }^{32,33}$ although there is some data to support the benefit of using low concentrations and large injection volumes of botulinum toxin at multiple muscular sites. ${ }^{30}$

\section{NSAIDs}

NSAIDs are indicated for mild-to-moderate acute inflammatory conditions. Commonly used NSAIDs include ibuprofen and naproxen. NSAIDs should be used by the patient for a minimum of 2 weeks, with time-contingent usage as opposed to dosing based on the presence of pain..$^{29}$ Long-term NSAID use is not recommended as long as the activity resulting in the inflammatory process can be reduced. In some chronic arthritic cases, the long-term use of NSAIDs, such as the COX-2 inhibitors, including celecoxib, may be considered; however, possible side effects, such as gastrointestinal upset, should be taken into account.

\section{Local anesthetics}

Local anesthetics are primarily used when a myofascial trigger point is present. Myofascial trigger points are usually detected in the mastication muscles, but can also be found in numerous other muscles, such as the splenius capitis and upper trapezius. Due to its low toxicity to muscles, $1 \%$ procaine $(1 \mathrm{cc})$ is recommended, but $1 \%$ or $2 \%$ lidocaine is also commonly used. ${ }^{1,31}$ The trigger point injection technique involves locating the trigger point, which is usually found in a taut band of muscle, and needling the area. ${ }^{10}$ The patient should be instructed that the muscles may be sore for the first 48 hours after the injection, but should begin to improve thereafter. The efficacy of trigger point injections is highly variable and dependent, for the most part, on the patient's compliance with a strict physical therapy regimen in conjunction with the injections. In addition, local anesthetics can be used to block the likely source of pain to confirm a diagnosis.

\section{TMJ injections}

Intracapsular injection of corticosteroids significantly reduces TMJ pain..$^{34}$ It is indicated for acute and painful arthritic TMJ that has not responded to other modalities of treatment ${ }^{12}$ and when the joint is still acutely inflamed, such as in the case of polyarthritic disorders and in acute disc displacements without reduction. ${ }^{35-37}$ The use of triamcinolone or dexamethasone, in addition to $2 \%$ lidocaine without epinephrine, is generally used for TMJ injections (Figure 2). Tomograms of the TMJ or other radiographic studies are required prior to injecting into the joint space. It has been suggested in animal studies that steroid injections may increase osteoclastic activity. ${ }^{38}$ There is no evidence that a single steroid injection causes damage; however, multiple injections may do, ${ }^{39}$ therefore the quantity of steroid injections should be carefully considered due to the possibility of bone resorption in the site of injection.

Injections of sodium hyaluronate in osteoarthritis of the knee has shown improvement of symptoms; ${ }^{40}$ however, results for the management of TMD have been inconclusive and more studies are warranted. ${ }^{41,42}$

\section{Muscle relaxants}

Muscle relaxants may be prescribed for acute muscle tension associated with TMJ disorders. ${ }^{31}$ These are commonly taken at night before bed, due to possible associated drowsiness. Thus, for patients with poor sleep patterns, these drugs are particularly helpful in alleviating insomnia in addition to their muscle-pain preventive properties. A commonly used and effective muscle relaxant is cyclobenzaprine, ${ }^{43}$ started at lower dosages (5-10 mg) and taken 1-2 hours before bedtime.

\section{Antidepressants}

Tricyclic antidepressants like amitriptyline and nortriptyline may be used for more chronic MFP. ${ }^{21,31}$ In addition, they can be prescribed for the TMD patient who has tension-

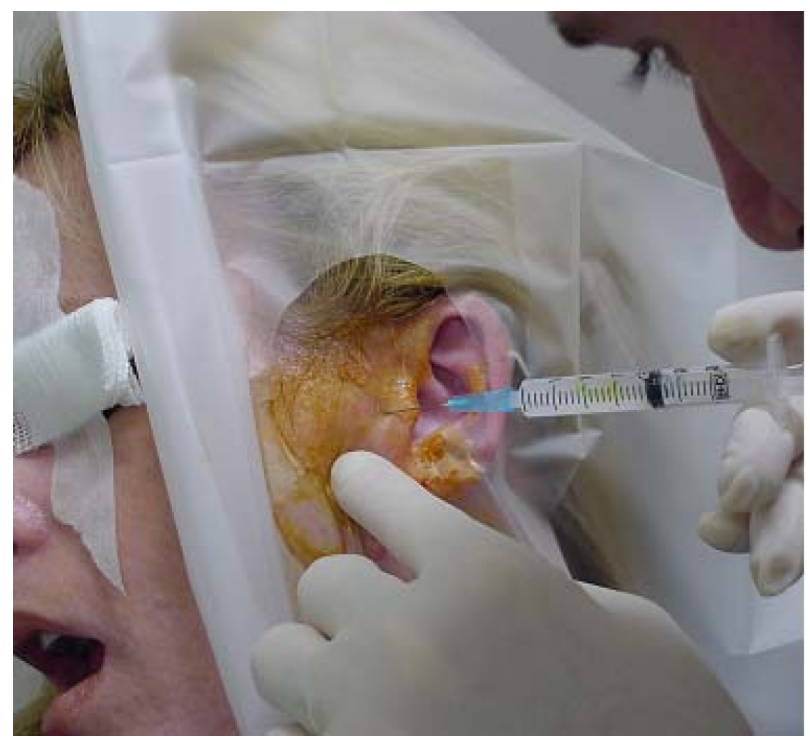

Figure 2 Temporomandibular joint injection. 
type headache (TTH), depression, poor sleep, and/or poor appetite. It is important to inform the patient that these medications are used in dosages that will not usually have anti-depressive effects when prescribed to treat muscle pain and/or headaches. Nortriptyline at usual doses of 10-30 mg and amitriptyline at doses of 10-25 mg should be gradually tapered up until the desired therapeutic effect is achieved or side effects develop, such as drowsiness, dry mouth, or weight gain. The tricyclic antidepressants have anti-nociceptive effects as well as maintaining the patient in deeper stages of sleep. Caution should be used in patients who have comorbid heart conditions, concurrent psychotropic use, and/or psychiatric illness, eg, bipolar disorder. ${ }^{44}$

\section{Occlusal appliance therapy}

Oral appliances (OAs) are processed acrylic devices that have been used for the management of TMD for years, with different designs. Studies have reported a reduction in TMD symptoms or at least sufficient evidence to justify their use for myalgia and arthralgia of the masticatory system. ${ }^{45-49}$ In an extensive review about the use of OAs and the management of TMD, it was concluded that OAs are still regarded as a useful adjunct therapy for some TMD cases. ${ }^{50}$

Stabilization appliances (flat plane splints) (Figure 3) are used for the purpose of equally distributing jaw parafunctional forces, reducing the forces placed on the masticatory muscles, and protecting the occlusal surfaces of the teeth from chronic nocturnal bruxing. ${ }^{51}$ For the case of nocturnal bruxism, OAs will protect the teeth from excessive tooth wear but may not stop parafunctional habits; they may, however, decrease the frequency, duration, and intensity of these habits. ${ }^{50,52,53}$ Usually, the patient is instructed to wear the splint only at night as long as parafunctional activity is controlled during the day with education and bite relation awareness, teaching the patient to be aware of when they are clenching their teeth during the day. The splint should cover all of the maxillary or mandibular teeth and have bilateral posterior contacts with little to no anterior contacts. The stabilization

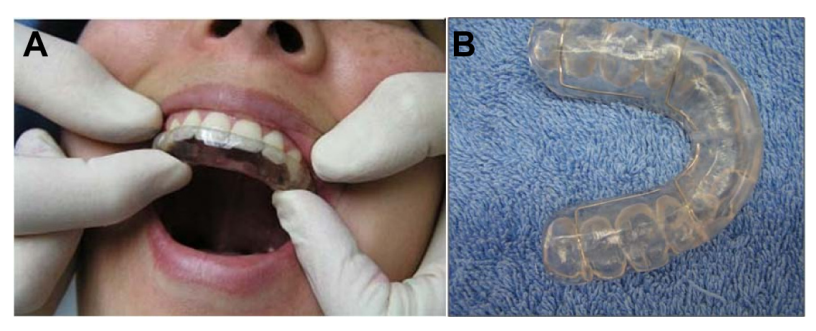

Figure 3 Maxillary stabilization splint. appliance should feel comfortable to the patient when fitted for the first time and be re-evaluated after 1 week. Adjustments should continue every 3-6 months due to changes that may result in the form and function of the splint due to chronic bruxing.

Anterior repositioning splint prescription varies among clinicians, but it is usually used for the chronic intermittent closed-locking patient. ${ }^{51}$ With the possibility of permanent occlusal and bite changes with long-term use of repositioning appliances, short-term ( 6 weeks) use of this appliance is strongly recommended in addition to close monitoring. If bite changes start to develop, then the patient should be instructed to discontinue the use of the splint and the splint may need to be converted to a stabilization non-repositioning appliance. A few patients may experience increased pain with the use of a splint. In this case, the splint and the initial diagnosis should be re-evaluated and, if the pain persists, discontinuation of the splint is recommended.

In a systematic review and meta-analysis of randomized controlled trials, it was found that well-adjusted hard stabilization appliances are more effective in treating joint and muscle pain when compared with the use of no appliance, soft stabilization appliances, anterior bite appliances, and non-occluding appliances. ${ }^{50}$ Even though these OAs presented some evidence of reducing joint and muscle pains, the potential adverse events (eg, occlusal changes) were higher. ${ }^{49}$

\section{Occlusal adjustment}

There is not enough evidence to show that occlusal adjustments are useful in treating or preventing TMD. ${ }^{54}$ As a general rule, TMD should be treated in a conservative manner and occlusal adjustments are an irreversible modality.

\section{Surgical care}

TMJ surgery is only indicated when non-surgical therapy has been ineffective, and it is not indicated in patients who are asymptomatic or mildly symptomatic or as a preventive measure. ${ }^{55}$ Surgical recommendations, such as arthrocentesis and arthroscopy, depend on the degree of internal derangement as well as previous TMJ treatment history in addition to moderate-to-severe pain and disabling dysfunction. ${ }^{55}$ It is important to discourage patients from undergoing surgical procedures if physical medicine, pharmacological management, and splint therapy have not been attempted. Working closely with an oral and maxillofacial surgeon who has expertise in TMJ surgery is highly advisable in dealing with this particular group of patients. 
Arthrocentesis is a conservative treatment that involves an intra-articular lavage with or without deposit of corticosteroids that is useful when there are intra-articular restrictions to movement, as in disc displacement without reduction. ${ }^{56}$ This procedure is often used with mandibular manipulation and is recommended for patients who have joint restrictions and for those individuals who have developed an acute or chronic closed lock. ${ }^{57}$

Arthroscopy is a closed surgical procedure that allows direct observation and sampling of joint tissue, useful in hypomobility due to joint derangement ${ }^{58}$ as well as fibrosis..$^{59}$ It is performed mainly in the upper joint space and is utilized primarily for lysis and lavage but also for ablation of adhesions and biopsy.

Arthrotomy is an open surgical procedure that modifies joint anatomy, such as total or partial joint reconstruction or replacement, which is required for the patient who has advanced TMD that meets the surgical criteria and has been refractory to other modalities. ${ }^{12}$ It is used in cases of neoplasia, bony or fibrous ankylosis, severe chronic arthritis, and severe chronic dislocations. ${ }^{58}$ It is important to work closely with an experienced TMJ surgeon to assess the necessity of this procedure if other conservative treatments have not produced positive results.

\section{Acupuncture and TMD}

Acupuncture has been studied as a complementary and alternative medicine treatment modality for various orofacial pain disorders, mostly those of musculoskeletal origin. Acupuncture is a form of Traditional Chinese Medicine (TCM) that involves the stimulation of acupuncture points that are thought to stimulate the flow of energy believed to be blocked. It has been proposed that the reason why acupuncture research has not been as definitive about its benefits in pain treatment is because these studies often fail to include other treatments, such as herbal remedies and Qigong. ${ }^{60}$ A study that focused on TMD showed reductions in pain and, more importantly, a reduction in NSAID use in subjects who had been treated with traditional acupuncture. ${ }^{60}$ Further research compared TCM including acupuncture to specialty care that included self-care, patient education, occlusal splint therapy, physical therapy, and psychosocial counseling and found that the TCM arm had a significantly greater reduction in pain and psychosocially contributing factors. ${ }^{61}$ In addition, MFP, when teased apart from TMD, has been shown to benefit from acupuncture when compared to a sham acupuncture procedure. ${ }^{62}$ It is crucial to educate MFP patients about the difference between acupuncture and traditional trigger point injection therapy, as patients may confuse the two because of the similarity of the procedures. Acupuncture appears to be a beneficial treatment in conjunction with traditional therapies for TMD and perhaps as an alternative if pharmacological treatment is contraindicated.

\section{Neuropathic pain}

Basic and clinical research support that neuroplastic changes involving the peripheral and central nervous system as well as immune mechanisms are involved in the development and maintenance of chronic neuropathic pain. ${ }^{63}$ It has been estimated that the incidence of chronic orofacial neuropathic pain is five to ten per 100,000 people ${ }^{64-66}$ Commonly, neuropathic pain conditions in the orofacial region are divided into episodic pain disorders, including trigeminal neuralgia (TN) and glossopharyngeal neuralgia, and continuous pain disorders that frequently result from deafferentation after injury in the peripheral and central nervous system, which is the case in neuromas and idiopathic trigeminal neuropathic pains such as atypical odontalgia (AO). There is considerable variability in prevalence, cause, and treatment of these disorders. More detailed reviews on neuropathic pains classification, etiology, and pathophysiology can be found elsewhere. 12,67,68

There are still limited data in regard to the treatment of trigeminal neuropathic pain. Its management is based on the evidence associated with pain management in other parts of the body. Good reference guides are those by Dworkin et al ${ }^{69}$ and Zakrzewska. ${ }^{70}$

The use of anticonvulsant medications has shown to be effective in the management of trigeminal neuropathic pain, and they are the first-line treatment choice for the management of neuralgic type of pains. ${ }^{70-72}$ Tricyclic antidepressants and serotonin noradrenaline reuptake inhibitors, as well as topical medications such as capsaicin and lidocaine, ${ }^{70,73}$ are used for the more continuous type of pain, such as in the case of idiopathic trigeminal neuropathic pain, for example, in $\mathrm{AO}^{74,75}$

\section{Trigeminal neuralgia}

TN is a chronic paroxysmal neuropathic pain condition that is described as a severe, lancinating, and electric-like unilateral pain. It is localized most often to the second and third distributions of the trigeminal nerve (V2 and V3) intraorally and extraorally and can present in both distributions at the same time. There is usually a trigger zone in the trigeminal distribution which, when stimulated, can result in an excruciatingly painful attack. The pain attacks last seconds to minutes and numerous pain episodes can be present daily. TN commonly 
goes through periods of remission where the pain can remit for months or even longer. ${ }^{12,66,76}$

The etiology of TN is often related to vascular compression ${ }^{77}$ that may result in focal demyelination. ${ }^{78}$ The superior cerebellar artery compression on the trigeminal root has been shown to be responsible for attacks of TN pain; ${ }^{79}$ however, nonvascular compression by a cerebellopontine angle neoplasm, such as acoustic neuromas, meningiomas, cholesteatomas, and neurofibromas, have also been shown to result in TN attacks. ${ }^{80,81} \mathrm{~A}$ cranial nerve exam can demonstrate other neural deficits that may be present due to a mass pressing on the trigeminal root. Therefore, magnetic resonance imaging (MRI) and computed tomography (CT) imaging of the brain should be requested in order to rule out any intracranial pathology. ${ }^{76}$ Furthermore, myelin loss due to multiple sclerosis has been shown to be a causative disorder related to the paroxysmal pain firing of TN attacks. ${ }^{82}$

Antiepileptic medications are the drugs of choice for the management of TN. Carbamazepine, oxcarbazepine, and gabapentin are commonly used as first-line medications. ${ }^{66,70}$ Carbamazepine, evaluated in a systematic review, has been shown to be the most effective treatment. ${ }^{71}$ If these medications are not effective, or if the therapeutic range cannot be achieved due to side effects, then doses should be lowered and second-line drugs, such as baclofen ${ }^{83}$ and lamotrigine, ${ }^{84}$ may be added to reduce the pain attacks. It is best to reduce the pain attacks completely with multiple medications if necessary. After achieving pain-free status and monitoring for pain attacks for a minimum of 3-6 months, a slow taper off of medication will demonstrate if the TN has gone into remission. If pain attacks recur, then pharmacologic management should immediately be reinstituted. If medications are no longer effective or if unmanageable side effects develop, then neurosurgical options, such as microvascular decompression or gamma knife radiosurgery, may be considered. ${ }^{85}$

\section{Glossopharyngeal neuralgia}

Glossopharyngeal neuralgia is a rare condition associated with pain in the area supplied by the glossopharyngeal nerve. ${ }^{86}$ Painful sites may include the nasopharynx, posterior part of the tongue, throat, tonsil, larynx, and ear. This disorder presents shooting paroxysms of pain that can occur multiple times a day with stimulation of the oropharyngeal region. ${ }^{87}$ Common triggers may include mechanical stimulation of the trigger zone as well as activities including chewing, swallowing, coughing, talking, and head movement. The painful episodes may continue for months and then spontaneously go into remission. Due to the proximity of the vagal sensory nerves, glossopharyngeal neuralgia may coincide with a cardiac dysrhythmia such as bradycardia, asystole, and syncope. ${ }^{88}$ Diagnosis may be confirmed by blocking the tonsillar and pharyngeal region with topical or local anesthetics. Imaging with a CT scan of the head and a brain MRI should be conducted to rule out pathology related to the nerve compression and possible oropharyngeal carcinoma. Pharmacologic treatment of glossopharyngeal neuralgia is similar to that for TN and may include the use of antiepileptic medications. ${ }^{89}$ If medication management fails, then surgical procedures may be considered, such as a microvascular decompression to remove pressure from the glossopharyngeal nerve, radiofrequency thermocoagulation, gamma knife radiosurgery, or rhizotomy. ${ }^{86,90}$

\section{Peripheral trigeminal neuropathic pain}

Peripheral neuropathic pain can arise as a result of a traumatic nerve injury resulting in chronic aching, continuous burning-like pain at the site of the injury. ${ }^{91}$ When a nerve injury occurs, the transected nerve will sometimes attempt to restore itself through axonal sprouting, resulting in a traumatic neuroma. ${ }^{92,93}$ Diagnosis can be made through tapping (Tinel's sign) or lightly pressing on the suspected site of the neuroma. In addition, allodynia and hyperalgesia will often be present in the area of the nerve injury or adjacent to it. ${ }^{91}$ It is recommended to perform a diagnostic block of the painful site with topical anesthetic first (eg, benzocaine) followed by a somatic block with local anesthetic (eg, lidocaine injection). ${ }^{91}$ If either of these blocks reduce or alleviate the pain, then topical creams or ointments may be utilized to treat the pain. The use of topical medications for the management of neuropathic pain is a good modality that reduces potential side effects of the systemic route. ${ }^{73}$ Capsaicin is a common locally acting pharmacologic agent that can be utilized in cream or gel form, normally at a concentration ranging from $0.025 \%-0.05 \%{ }^{95}$ mixed with benzocaine $20 \%$ and applied with the use of a stent that covers the affected area (neurosensory stent). Recently, $8 \%$ capsaicin has been approved in the US and Europe for application directly into the skin, and has proved to be effective in alleviating pain. ${ }^{95}$ In addition, compounding pharmacies can create a cream that may include analgesics/sedatives such as ketamine, NSAIDs such as diclofenac, anticonvulsant drugs such as gabapentin and carbamazepine, and tricyclic antidepressant medications such as nortriptyline and amitriptyline. ${ }^{73,96}$ 


\section{Centralized trigeminal neuropathic pain}

Prolonged stimulation of peripheral nociceptors may eventually lead to central neural changes. ${ }^{63,97}$ The pain in these cases is described as continuous, aching, and burning, with evidence of hyperalgesia and allodynia. ${ }^{98}$ Diagnostic local anesthetic blocking of the affected site usually does not alleviate the pain in centralized neuropathic pain, thus treatment is conducted with centrally acting systemic medications. Antiepileptic drugs, such as gabapentin and valproic acid, in combination with tricyclic antidepressants such as amitriptyline, may reduce pain, ${ }^{70}$ but often treatment of this condition is difficult.

\section{Atypical odontalgia}

$\mathrm{AO}$ is a centralized trigeminal neuropathy often localized in a tooth or tooth area that is frequently misdiagnosed, leading to unnecessary dental treatments in attempts to relieve the pain. ${ }^{75} \mathrm{AO}$ is described as a persistent idiopathic pain that does not fulfill the diagnostic criteria for cranial neuralgias and which is not attributed to another disorder, ${ }^{99}$ and can be throbbing and burning in nature. ${ }^{12}$ The pharmacological management of AO may include topical and systemic medications. If the pain is localized to a peripheral origin and the diagnostic block gives an equivocal response but a decrease in pain, a topical medication can be used and a neurosensory stent can be fabricated. Systemic approaches, such as tricyclic antidepressants, calcium channel blockers (pregabalin and gabapentin), sodium channel blockers (carbamazepine), and antiepileptics such as topiramate, can be used for the management of this condition. ${ }^{69,74}$ The management of $\mathrm{AO}$ is very challenging, and a multidisciplinary approach is necessary, which should include orofacial pain specialists and neurologists in addition to psychiatric and psychological evaluations in order to identify comorbidities with depression and anxiety. ${ }^{74}$

\section{Headache}

Another source of nonodontogenic toothaches and orofacial pains may present as a disturbance of the trigeminovascular system. Migraine is commonly thought of as a headache that is unilateral and that causes pain behind the eye, neck, and cranium; however, migraine headaches can also present in the lower part of the face, particularly in the teeth. ${ }^{98-100}$ It is very important that the orofacial pain clinician is aware of the possibility of this localization in addition to the clinical features that a migraine presents to avoid misdiagnosis as an odontogenic toothache or other type of orofacial pain, leading to improper management.
Primary headaches, such as migraine and TTH, are also disorders mediated by the trigeminal system that can be chronic and disabling, affecting over $15 \%$ of the US population at any one time and costing the US economy over $\$ 19.6$ billion a year. ${ }^{102}$ Migraine is a primary disorder of the brain explained as a neurovascular disorder in which neural events result in meningeal blood vessel dilation, which results in further nociceptive activation of the trigeminovascular system. ${ }^{103}$ The pathophysiology of migraine is still not completely understood, but it is known that key anatomical peripheral and central structures are involved. The trigeminovascular system consists of the dura mater that surrounds the meninges and spinal cord, the dural meningeal blood vessels (cranial vasculature), and the innervations of these structures provided by the ophthalmic branch (V1) of the trigeminal nerve and its afferent connection to the trigeminal nucleus caudalis (TNC) in the central nervous system, in addition to a reflex connection from the trigeminal nucleus to the parasympathetic outflow to the cranial vasculature through the superior salivatory nucleus. ${ }^{103,104}$

The nociceptive (pain) information of these structures convey information to the TNC, brainstem, and higher processing centers. ${ }^{103}$ The TNC also receives cervical inputs. Stimulation of the dura mater extends to the $\mathrm{C} 2$ and $\mathrm{C} 3$ regions, and is collectively described as the trigeminocervical complex (TCC). This anatomical relationship may explain why a migraine headache can sometimes be felt in the neck area. ${ }^{105-107}$

Primary headaches, particularly migraine, are believed to involve activation and sensitization of the trigeminovascular system, specifically the afferent meningeal nociceptor projections to the ophthalmic division of the trigeminal nerve, ${ }^{108}$ and this is thought to cause the release of vasoactive neuropeptides such as substance P (SP), neurokinin A (NKA), and calcitonin gene-related peptide (CGRP), which is elevated during a chronic migraine attack. ${ }^{109}$ What drives the trigeminovascular activation is still not clear, but it has been hypothesized that a dysfunction within nuclei of the brainstem and diencephalon may contribute to activation of this system, thereby relaying nociceptive information to other central structures. ${ }^{103}$ Trigeminal nerve release of CGRP is known to aid in the process of neurogenic inflammation, facilitating pain transmission leading to allodynia and hyperalgesia. ${ }^{110-112}$ These nociceptive mediators will induce edema, mast cell activation, and further sensitization of the trigeminovascular system. ${ }^{113}$

\section{Facial migraine}

In the new International Classification of Headache Disorders 3rd edition (ICHD-3 beta version) in the comments 
to section 1.1 ("Migraine without aura") facial migraine is mentioned as a subset of patients who present with the typical migraine headache, but localized in the face and not as a subtype. ${ }^{99}$ Facial migraine may follow the diagnostic criteria of migraine without aura (ICHD-3 1.1), which is described as a recurrent headache of moderate-to-severe intensity that lasts from 4-72 hours, with a pulsating quality, which is unilateral in location, aggravated by routine physical activity, and associated with nausea and/or phonophobia and photophobia. ${ }^{99}$

The ophthalmic division of the trigeminal nerve innervates most of the cranial structures: this could explain the reason why most migraine sufferers feel pain in the periorbital region and behind their eye. In facial migraine, however, the pain is localized in the lower part of the face. Migraine localized in the area of the maxillary branch distribution (V2) has been reported. ${ }^{101,114,115} \mathrm{~V} 2$ gives rise to the nervus meningeus medius, which innervates the dura mater of the anterior floor of the middle fossa, and this may explain the localization of the pain in the maxillary area. Migraine symptomatology localized on the V3 territory has also been reported, ${ }^{101,114,115}$ and this could be explained since it is well recognized that stimulation of the dura mater in animals during electrophysiological experiments, and in humans during neurosurgery, induces pain in any of the three divisions of the trigeminal nerve. ${ }^{101,116}$ More detailed reviews on migraine pathophysiology can be found elsewhere. ${ }^{103,117}$

\section{Management}

The management of migraine comprises pharmacological and nonpharmacological approaches. It is imperative that the treatment approach of migraine always includes a complete medical evaluation performed by the neurologist to rule out a secondary cause of the headache, such as systemic disease, tumors, or cerebrovascular abnormalities.

\section{Nonpharmacological approaches}

Patients need to be educated about the pain they are experiencing. When the pain is localized in the lower half of the face and/or in a tooth/teeth area (facial migraine), the patient should be assured that, even though the experienced pain may be severe and throbbing, it is not a toothache or related dental problem. This is extremely important since it will prevent unnecessary dental procedures due to misdiagnosis as odontogenic toothache or other orofacial pain.

Facial migraine is the same migraine headache described in the ICDH-3 (beta version) but with a different localization, therefore requiring that the same management protocol be followed. It is recommended to have the patient identify any trigger factors that may start the migraine attack. A good method by which the patient can provide this information is with the use of a pain diary, in which the patient keeps a record of the characteristics of the headache episodes along with the circumstances that made them appear. As soon as the patient can identify the possible triggers, then they are instructed to avoid or address them by, for example, a change in diet, sleep hygiene, or stress management. This is a great opportunity for the patient to realize that lifestyle changes may greatly influence their headaches and subsequently feel more in control of the disorder.

Other nonpharmacological methods that have proved useful for migraine and TTH are biofeedback, relaxation techniques, hypnosis, and psychological therapies. ${ }^{18,119}$

\section{Pharmacological approaches}

As described above, the TNC is a crucial anatomical relay center for conveying sensory information, predominantly nociceptive, coming from the orofacial region, the head and its cranial vasculature, to higher pain processing centers in the brain; in addition, it gives and receives projections from the superior salivatory nucleus and structures from the descending inhibitory system, such as the ventrolateral periaqueductal gray and rostral ventromedial medulla. ${ }^{103}$ These anatomical connections have positioned the TNC as a therapeutical target to potentially decrease or inhibit trigeminovascular nociceptive activation and further sensitization. ${ }^{120}$

The same medications used for the management of migraine are used for the management of facial migraine, since it is the same disorder and same pathophysiology but different headache localization (face). If the migraine attack occurs less than twice per month, then an abortive medication should be considered. If the migraine attack is more frequent, it is best managed with preventive medications.

\section{Abortive medications}

Abortive medications are the first line of treatment for the acute treatment of migraine. The use of NSAIDs, such as naproxen sodium and ibuprofen, has been shown to be probably effective in alleviating a headache attack; ${ }^{121}$ however, patients taking NSAIDs on a daily or regular basis are at risk of exacerbating their existent headache and developing medication overuse headaches. ${ }^{99}$

Ergotamine derivatives, such as dihydroergotamine (DHE), have been used for years for the treatment of moderate to severe migraine; ${ }^{122}$ however, triptans, because of their better tolerability and pharmacological specificity, have replaced 
ergotamine derivatives in the majority of cases. ${ }^{123}$ DHE is a $5-\mathrm{HT}_{1 \mathrm{~B}}$ and $5-\mathrm{HT}_{1 \mathrm{D}}$ agonist, ${ }^{124}$ as well as acting at other receptors, and is useful in patients who have not responded to triptan therapy. ${ }^{122} \mathrm{DHE}$ is available in intranasal ${ }^{125}$ and injectable preparations, the latter in particular being popularly used as an abortive agent in the emergency room. ${ }^{126}$

Serotonin 5-HT $\mathrm{HB}_{1 \mathrm{~B} / \mathrm{D}}$ receptor agonists (triptans), such as sumatriptan, are newer established medications for the acute treatment of migraine. ${ }^{127,128}$ Studies have shown that they affect neuronal activation, inhibiting the presynaptic release of CGRP at the TCC, and also act in the ventrolateral periaqueductal gray and the thalamus. ${ }^{103,129} 5-\mathrm{HT}_{1 \mathrm{~B} / 1 \mathrm{D}}$ receptors are localized on the trigeminal ganglion in humans and rodents ${ }^{130-132}$ and at the level of the TNC in humans. ${ }^{133-135} 5-\mathrm{HT}_{1 \mathrm{~B}}$ receptors are localized on human intracranial arteries. ${ }^{133}$ Sumatriptan has been shown to prevent central sensitization of TCC neurons, but not abort central sensitization. ${ }^{136,137}$ This may explain why triptans are effective when they are taken at the first sign of a migraine.

In addition to oral dosing formulations, subcutaneous and intranasal formulations offer a fast onset of action and are a good alternative for patients who experience gastrointestinal effects. The different pharmacokinetics between triptans should be considered when choosing the appropriate one for a patient.

New combination preparations, such as sumatriptan with naproxen sodium, have shown additive effects in improving pain relief and migraine-associated symptoms, such as phonophobia, photophobia, and nausea, when compared with monotherapy, as well as good tolerability in the acute management of migraine. ${ }^{138,139}$

Triptans can induce cardiovascular and cerebrovascular effects because of their vasoconstrictor properties, therefore they are contraindicated in patients with disorders in these systems. ${ }^{140}$ However, new medications in development such as CGRP receptor antagonists, including oral telcagepant, have shown to be a good migraine abortive without the vascular effects. ${ }^{141}$ Evidence has shown that the $5-\mathrm{HT}_{1 \mathrm{~F}}$ receptor is another promising new target in the treatment of migraine: lasmiditan, a 5-HT ${ }_{1 \mathrm{~F}}$ receptor agonist, has shown good clinical efficacy for acute migraine treatment in doubleblind placebo controlled trials. ${ }^{142,143}$

\section{Preventives}

Patients who have frequent migraine attacks, such as 15 headache days per month, can benefit from preventive therapy. ${ }^{99}$ The mechanism of action of the current preventive medications is not, however, well understood. Medications that have proven beneficial are beta adrenergic blockers such as propranolol and atenolol; calcium channel blockers such as verapamil and flunarizine; tricyclic antidepressants such as amitriptyline; serotonin antagonists such as methysergide; and antiepileptics such as topiramate and valproate. ${ }^{144}$

Newer treatment strategies have been shown to be promising. The use of botulinum toxin injections for migraine prophylaxis and the management of chronic migraine and TTH have been shown to be effective and well tolerated. ${ }^{145-148}$ In addition, neuromodulative procedures, such as occipital nerve stimulation approaches, have been shown to be effective in the management of refractory headaches such as chronic migraine and cluster headache in which pain-free periods (weeks) can be accomplished. ${ }^{149,150}$ More comprehensive reviews of preventive options for migraine can be found elsewhere. ${ }^{44,151}$

\section{Tension type headache}

TTH is the most common primary headache disorder in the general population. ${ }^{152}$ Its pathophysiology remains unclear, but peripheral and central mechanisms are likely to be involved. A model has been proposed in which interaction between the limbic system, the descending inhibitory system, and peripheral inputs, such as those coming from the intracranial vasculature and myofascial inputs, may result in TTH. ${ }^{153}$

The patient may describe the headache as a tight headband compressing their head with a dull, non-pulsating quality. The headache is bilateral with a mild-to-moderate intensity and will not worsen with routine physical activity. It can present as episodic attacks, but can evolve to a more chronic state. ${ }^{99}$ Sometimes the headache can be associated with pericranial tenderness. Muscles that are tender to palpation include the temporalis muscle and cervical muscles, such as the splenius, sternocleidomastoid, and upper trapezius muscles. ${ }^{99,154,155}$ Headache associated with myofascial trigger points can meet the criteria for episodic and chronic TTH. ${ }^{156,157}$ This is very important to note during examination, since treatment should be oriented to address the MFP condition. The use of physical therapy and trigger point injection therapy is useful. ${ }^{1}$

The management of TTH involves nonpharmacological and pharmacological approaches, as observed for migraine. Changes in lifestyle such as sleep hygiene, detection of triggers with a pain diary, as well as stress management and relaxation techniques, have been shown to be beneficial. ${ }^{18,158}$ Pharmacological approaches, such as the use of NSAIDs as 
well as tricyclic antidepressants in addition to botulinum toxin injections, have proved useful. ${ }^{145,146,159,160}$

\section{Headache and TMD}

It is known that headache and orofacial pain disorders, such as TMD, are highly prevalent conditions in the general population. ${ }^{161,162}$ Evidence suggests that a clinical comorbidity between primary headaches and TMD exists. ${ }^{163,164}$ Epidemiological studies have shown that TMD symptomatology is more common in patients with primary headaches such as migraine, episodic TTH, and chronic daily headache, ${ }^{163,164}$ where the prevalence of primary headache, particularly migraine, was increased in patients with TMD. ${ }^{165}$ In addition, patients with headache and orofacial pain disorders of musculoskeletal origin also present a higher disability impact. ${ }^{163}$ It can be hypothesized that extracranial trigeminal nociceptive inputs arising from the craniofacial structures as a result of a TMD may influence the activation of the trigeminovascular system, since these nociceptive inputs convey in TNC where intracranial inputs do. Existing TMD may, therefore, influ- ence and/or exacerbate a headache disorder, and a headache disorder may exacerbate a TMD condition (Figure 4). It is very important, therefore, that, during treatment, such comorbidity is addressed. A relationship between the orofacial pain specialist and the neurologist (headache specialist) must be established, as management should be focused on addressing both, the headache and the TMD condition, since they considerably increase the prevalence of each other. ${ }^{163,164}$

\section{Trigeminal autonomic cephalalgias (TACs)}

Cluster headache, paroxysmal hemicranias, and shortlasting unilateral neuralgiform headache attacks with conjunctival injection and tearing are severe headaches that are not as common as migraine and that are characterized for their notorious parasympathetic autonomic symptoms. ${ }^{99,166}$ The typical localization of these headaches are the orbital, temporal or supraorbital regions but they can be present in the orofacial region such as in the mandible, TMJ, and dental areas. These headaches require neurological evaluation and management; therefore, it is

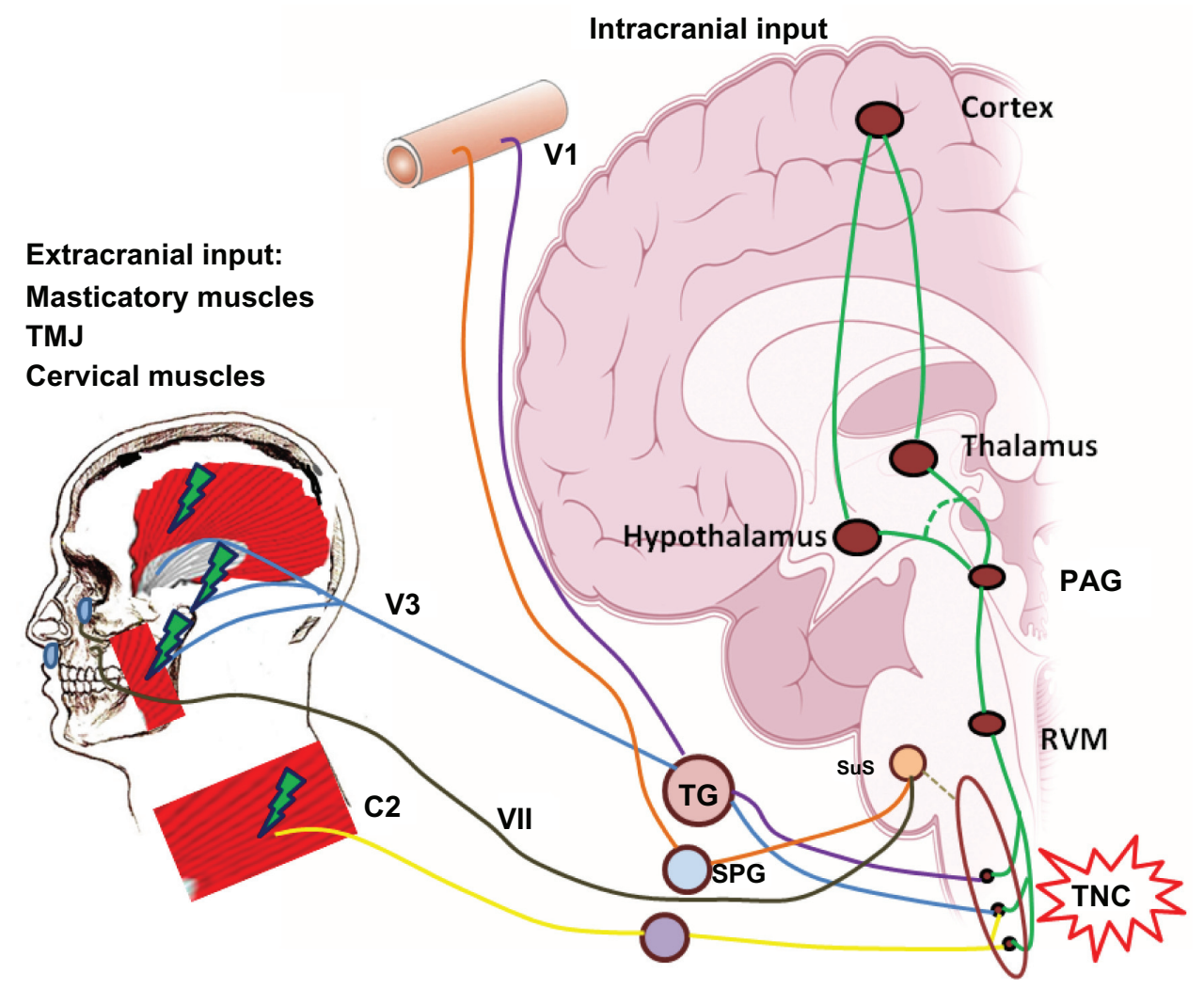

Figure 4 Relationship between temporomandibular disorders and headache.

Notes: Extracranial nociceptive inputs arising from craniofacial structures as a result of a temporomandibular disorder, as well as cervical input from the cervical muscles, may influence the activation of the trigeminovascular system. The commonality is that these nociceptive inputs converge on the TNC in the same way as do intracranial nociceptive inputs arising from the dural blood vessels and higher centers.

Abbreviations: C2, C2 region of the cervical spinal cord; PAG, ventrolateral periaqueductal gray; RVM, rostral ventromedial medulla; SPG, sphenopalatine ganglion; SuS, superior salivatory nucleus; TG, trigeminal ganglion; TMJ, temporomandibular joint; TNC, trigeminal nucleus caudalis; VII, facial nerve; VI, ophthalmic branch of the trigeminal nerve; $\mathrm{V} 3$, mandibular branch of the trigeminal nerve. 
of fundamental importance to make an appropriate differential diagnosis to avoid unnecessary dental treatments or being misdiagnosed as other types of orofacial pains of non neurovascular etiology. Detailed reviews of trigeminal autonomic cephalalgias and their treatment can be found elsewhere. ${ }^{166-168}$

\section{Conclusion}

Orofacial pain management can be challenging and the clinician should be aware of the different etiologies and characteristics of the diverse disorders of the orofacial region. The orofacial pain specialist has the experience and the knowledge to provide a correct diagnosis and management of these conditions. A multidisciplinary approach is ideal in the management of orofacial pain disorders.

Understanding the pain neurobiology of the trigeminal system is key to the development of better and safer therapeutics. It is necessary to stress the need for randomized controlled clinical trials that evaluate the efficacy of current and new therapies for the management of orofacial pains. New and exciting discoveries from the bench to the bedside will hopefully put an end to the burden of chronic orofacial pain conditions in the near future.

\section{Acknowledgment}

We thank Dr Simon Akerman for reviewing the draft of this manuscript.

\section{Disclosure}

The authors report no conflicts of interest in this work.

\section{References}

1. Okeson JP. Bell's Orofacial Pains. The Clinical Management of Orofacial Pain. 6th ed. Carol Stream, IL: Quintessence Publishing Co, Inc; 2005.

2. Okeson JP. The Classification of Orofacial Pains. Oral Maxillofac Surg Clin North Am. 2008;20(2):133-144.

3. McNeill C. Temporomandibular Disorders: Guidelines for Classification, Assesment, and Management. 2nd ed. Chicago, IL: Quintessence Publishing Co, Inc; 1993.

4. Dworkin SF. Temporomandibular disorder (TMD) pain-related disability found related to depression, nonspecific physical symptoms, and pain duration at 3 international sites. J Evid Based Dent Pract. 2011;11(3): 143-144.

5. Dworkin SF, Huggins KH, LeResche L, et al. Epidemiology of signs and symptoms in temporomandibular disorders: clinical signs in cases and controls. J Am Dent Assoc. 1990;120(3):273-281.

6. Solberg W, Woo M, Houston J. Prevalence of mandibular dysfunction in young adults. J Am Dent Assoc. 1979;98(1):25-34.

7. Rasmussen OC. Description of population and progress of symptoms in a longitudinal study of temporomandibular arthropathy. Scand J Dent Res. 1981;89(2):196-203.

8. Könönen M, Waltimo A, Nyström M. Does clicking in adolescence lead to painful temporomandibular joint locking? Lancet. 1996;347(9008):1080-1081.
9. Guarda-Nardini L, Piccotti F, Mogno G, Favero L, Manfredini D. Agerelated differences in temporomandibular disorder diagnoses. Cranio. 2012;30(2):103-109.

10. Simons DG, Travel JG, Simons LS. Myofascial Pain and Dysfunction: The Trigger Point Manual. Upper Half of Body. 2nd ed. Atlanta, GA: Lippincott Williams \& Wilkins; 1998;1.

11. Sanitá PV, de Alencar Júnior FGP. Myofascial pain syndrome as a contributing factor in patients with chronic headaches. $J$ Musculoskelet Pain. 2009;17(1):15-25.

12. de Leeuw R. Temporomandibular Disorders. In: de Leeuw R, editor. Orofacial Pain Guidelines for Assesment, Diagnosis and Management. The American Academy of Orofacial Pain. 4th ed. Hanover Park, IL: Quintessence Publishing Co, Inc; 2008:158-176.

13. Clark GT, Seligman DA, Solberg WK, Pullinger AC. Guidelines for the examination and diagnosis of temporomandibular disorders. J Craniomandib Disord. 1989;3(1):7-14.

14. Bezuur JN, Habets LL, Jimenez Lopez V, Naeije M, Hansson TL. The recognition of craniomandibular disorders - a comparison between clinical and radiographic findings in eighty-nine subjects. J Oral Rehabil. 1988;15(3):215-221.

15. Ohrbach R, Gale EN. Pressure pain thresholds, clinical assessment, and differential diagnosis: reliability and validity in patients with myogenic pain. Pain. 1989;39(2):157-169.

16. Mejersjö C, Carlsson GE. Long-term results of treatment for temporomandibular joint pain-dysfunction. J Prosthet Dent. 1983;49(6): $809-815$.

17. Nickerson JW, Boering G. Natural course of osteoarthrosis as it relates to internal derangement of the temporomandibular joint. Oral Maxillofac Surg Clin North Am. 1989;1:27-45.

18. Mejersjö C, Carlsson GE. Analysis of factors influencing the longterm effect of treatment of TMJ-pain dysfunction. J Oral Rehabil. 1984;11(3):289-297.

19. Riley JL 3rd, Myers CD, Currie TP, et al. Self-care behaviors associated with myofascial temporomandibular disorder pain J Orofac Pain. 2007;21(3):194-202.

20. Randolph CS, Greene CS, Moretti R, Forbes D, Perry HT. Conservative management of temporomandibular disorders: a posttreatment comparison between patients from a university clinic and from private practice. Am J Orthod Dentofacial Orthop. 1990;98(1):77-82.

21. Graff-Radford SB. Myofascial pain: diagnosis and management. Curr Pain Headache Rep. 2004;8(6):463-467.

22. Danzig WN, Van Dyke AR. Physical therapy as an adjunct to temporomandibular joint therapy. J Prosthet Dent. 1983;49(1):96-99.

23. Kirk WS Jr, Calabrese DK. Clinical evaluation of physical therapy in the management of internal derangement of the temporomandibular joint. J Oral Maxillofac Surg. 1989;47(2):113-119.

24. Clark GT, Adachi NY, Dornan MR. Physical medicine procedures affect temporomandibular disorders: a review. J Am Dent Assoc. 1990;121(1):151-162.

25. Carlson CR, Okeson JP, Falace DA, Nitz AJ, Anderson D. Stretch-based relaxation and the reduction of EMG activity among masticatory muscle pain patients. J Craniomandib Disord. 1991;5(3):205-212.

26. Rodrigues D, Siriani AO, Bérzin F. Effect of conventional TENS on pain and electromyographic activity of masticatory muscles in TMD patients. Braz Oral Res. 2004;18(4):290-295.

27. Reeves JL. EMG-biofeedback reduction of tension headache: a cognitive skills-training approach. Biofeedback Self Regul. 1976;1(2):217-225.

28. Gangarosa L, Mahan PE. Pharmacologic management of TMD-MPDS. Ear Nose Throat J. 1982;61:670-678.

29. Gregg JM, Rugh JD. Pharmacological therapy. In: Mohl NDZ, George A, Carlsson, Gunnar E, Rugh, John D, editor. A Textbook of Occlusion. Chicago, IL: Quintessence; 1983:351-375.

30. Song PC, Schwartz J, Blitzer A. The emerging role of botulinum toxin in the treatment of temporomandibular disorders. Oral Dis. 2007;13(3):253-260.

31. Graff-Radford SB. Regional myofascial pain syndrome and headache: principles of diagnosis and management. Curr Pain Headache Rep. 2001;5(4):376-381. 
32. Ernberg M, Hedenberg-Magnusson B, List T, Svensson P. Efficacy of botulinum toxin type A for treatment of persistent myofascial TMD pain: a randomized, controlled, double-blind multicenter study. Pain. 2011;152(9):1988-1996.

33. Guarda-Nardini L, Stecco A, Stecco C, Masiero S, Manfredini D. Myofascial pain of the jaw muscles: comparison of short-term effectiveness of botulinum toxin injections and fascial manipulation technique. Cranio. 2012;30(2):95-102.

34. Wenneberg B, Kopp S, Gröndahl HG. Long-term effect of intraarticular injections of a glucocorticosteroid into the TMJ: a clinical and radiographic 8-year follow-up. J Craniomandib Disord. 1991;5(1): $11-18$.

35. Kopp S, Akerman S, Nilner M. Short-term effects of intra-articular sodium hyaluronate, glucocorticoid, and saline injections on rheumatoid arthritis of the temporomandibular joint. $J$ Craniomandib Disord. 1991;5(4):231-238.

36. Samiee A, Sabzerou D, Edalatpajouh F, Clark GT, Ram S. Temporomandibular joint injection with corticosteroid and local anesthetic for limited mouth opening. J Oral Sci. 2011;53(3):321-325.

37. Stoll ML, Good J, Sharpe T, et al. Intra-articular corticosteroid injections to the temporomandibular joints are safe and appear to be effective therapy in children with juvenile idiopathic arthritis. J Oral Maxillofac Surg. 2012;70(8):1802-1807.

38. El-Hakim IE, Abdel-Hamid IS, Bader A. Tempromandibular joint (TMJ) response to intra-articular dexamethasone injection following mechanical arthropathy: a histological study in rats. Nt J Oral Maxillofac Surg. 2005;34(3):305-310.

39. Toller PA. Use and misuse of intra-articular corticosteroids in treatment of temporomandibular joint pain. Proc R Soc Med. 1977;70(7): 461-463.

40. Divine JG, Zazulak BT, Hewett TE. Viscosupplementation for knee osteoarthritis: a systematic review. Clin Orthop Relat Res. 2007;455: $113-122$.

41. Li XD, Shi ZD, Tian WD. [An outcome analysis of two methods of intra-capsular injection of sodium hyaluronate for temporomandibular disorders]. Hua Xi Kou Qiang Yi Xue Za Zhi. 2004;22(2):135-137. Chinese.

42. Manfredini D, Piccotti F, Guarda-Nardini L. Hyaluronic acid in the treatment of TMJ disorders: a systematic review of the literature. Cranio. 2010;28(3):166-176.

43. Herman CR, Schiffman EL, Look JO, Rindal DB. The effectiveness of adding pharmacologic treatment with clonazepam or cyclobenzaprine to patient education and self-care for the treatment of jaw pain upon awakening: a randomized clinical trial. J Orofac Pain. 2002;16(1): 64-70.

44. Silberstein SD. Preventive migraine treatment. Neurol Clin. 2009; 27(2):429-443.

45. Clark GT. A critical evaluation of orthopedic interocclusal appliance therapy: effectiveness for specific symptoms. J Am Dent Assoc. 1984;108(3):364-368

46. Clark GT. A critical evaluation of orthopedic interocclusal appliance therapy: design, theory, and overall effectiveness. J Am Dent Assoc. 1984;108(3):359-364.

47. Tsuga K, Akagawa Y, Sakaguchi R, Tsuru H. A short-term evaluation of the effectiveness of stabilization-type occlusal splint therapy for specific symptoms of temporomandibular joint dysfunction syndrome. J Prosthet Dent. 1989;61(5):610-613.

48. Kreiner M, Betancor E, Clark GT. Occlusal stabilization appliances. Evidence of their efficacy. J Am Dent Assoc. 2001;132(6): 770-777.

49. Fricton J, Look JO, Wright E, et al. Systematic review and metaanalysis of randomized controlled trials evaluating intraoral orthopedic appliances for temporomandibular disorders. J Orofac Pain. 2010;24(3):237-254.

50. Klasser GD, Greene CS. Oral appliances in the management of temporomandibular disorders. Oral Surg Oral Med Oral Pathol Oral Radiol Endod. 2009;107(2):212-223.
51. Fricton J. Myogenous temporomandibular disorders: diagnostic and management considerations. Dent Clin North Am. 2007;51(1): $61-83$.

52. Clark GT, Beemsterboer PL, Solberg WK, Rugh JD. Nocturnal electromyographic evaluation of myofascial pain dysfunction in patients undergoing occlusal splint therapy. J Am Dent Assoc. 1979;99(4): 607-611.

53. Dube C, Rompre PH, Manzini C, Guitard F, de Grandmont P, Lavigne GJ. Quantitative polygraphic controlled study on efficacy and safety of oral splint devices in tooth-grinding subjects. $J$ Dent Res. 2004;83(5):398-403.

54. Koh H, Robinson PG. Occlusal adjustment for treating and preventing temporomandibular joint disorders. Cochrane Database Syst Rev. 2003;(1):CD003812.

55. [No authors listed]. Parameters of care for oral and maxillofacial surgery. A guide for practice, monitoring and evaluation (AAOMS Parameters of Care-92). American Association of Oral and Maxillofacial Surgeons. J Oral Maxillofac Surg. 1992;50(7 Suppl 2):i-xvi, 1-174.

56. Nitzan DW, Dolwick MF, Martinez GA. Temporomandibular joint arthrocentesis: a simplified treatment for severe, limited mouth opening. J Oral Maxillofac Surg. 1991;49(11):1163-1167; discussion $1168-1170$

57. Dimitroulis G, Dolwick MF, Martinez A. Temporomandibular joint arthrocentesis and lavage for the treatment of closed lock: a follow-up study. Br J Oral Maxillofac Surg. 1995;33(1):23-27.

58. Buckley MJ, Merrill RG, Braun TW. Surgical management of internal derangement of the temporomandibular joint. J Oral Maxillofac Surg. 1993;51(1 Suppl 1):20-27.

59. Blaustein D, Heffez L. Diagnostic arthroscopy of the temporomandibular joint. Part II. Arthroscopic findings of arthrographically diagnosed disk displacements. Oral Surg Oral Med Oral Pathol. 1988;65(2):135-141.

60. Elder C, Ritenbaugh C, Aickin M, et al. Reductions in pain medication use associated with traditional Chinese medicine for chronic pain. Perm J. 2012;16(3):18-23.

61. Ritenbaugh C, Hammerschlag R, Calabrese C, et al. A pilot whole systems clinical trial of traditional Chinese medicine and naturopathic medicine for the treatment of temporomandibular disorders. $J$ Altern Complement Med. 2008;14(5):475-487.

62. Shen YF, Younger J, Goddard G, Mackey S. Randomized clinical trial of acupuncture for myofascial pain of the jaw muscles. J Orofac Pain. 2009;23(4):353-359.

63. Romero-Reyes M, Graff-Radford S. Is there hope for chronic pain and headache? Headache. 2007;47(8):1262-1271.

64. Lipton JA, Ship JA, Larach-Robinson D. Estimated prevalence and distribution of reported orofacial pain in the United States. J Am Dent Assoc. 1993;124(10):115-121.

65. Marbach JJ. Medically unexplained chronic orofacial pain. Temporomandibular pain and dysfunction syndrome, orofacial phantom pain, burning mouth syndrome, and trigeminal neuralgia. Med Clin North Am. 1999;83(3):691-710.

66. Kitt CA, Gruber K, Davis M, Woolf CJ, Levine JD. Trigeminal neuralgia: opportunities for research and treatment. Pain. 2000;85(1):3-7.

67. Sarlani E, Balciunas BA, Grace EG. Orofacial pain - Part I: assessment and management of musculoskeletal and neuropathic causes. $A A C N$ Clin Issues. 2005;16(3):333-346.

68. Sarlani E, Balciunas BA, Grace EG. Orofacial Pain - Part II: assessment and management of vascular, neurovascular, idiopathic, secondary, and psychogenic causes. AACN Clin Issues. 2005;16(3):347-358.

69. Dworkin RH, O'Connor AB, Audette J, et al. Recommendations for the pharmacological management of neuropathic pain: an overview and literature update. Mayo Clin Proc. 2010;85(Suppl 3):S3-S14.

70. Zakrzewska JM. Medical management of trigeminal neuropathic pains. Expert Opin Pharmacother. 2010;11(8):1239-1254.

71. Reisner L, Pettengill CA. The use of anticonvulsants in orofacial pain. Oral Surg Oral Med Oral Pathol Oral Radiol Endod. 2001;91(1):2-7. 
72. Martin WJ, Forouzanfar T. The efficacy of anticonvulsants on orofacial pain: a systematic review. Oral Surg Oral Med Oral Pathol Oral Radiol Endod. 2011;111(5):627-633.

73. Bramwell BL. Bs Pharm Rph. Topical orofacial medications for neuropathic pain. Int J Pharm Compd. 2010;14(3):200-203.

74. Baad-Hansen L. Atypical odontalgia - pathophysiology and clinical management. J Oral Rehabil. 2008;35(1):1-11.

75. Patel SB, Boros AL, Kumar SK. Atypical odontalgia - an update. J Calif Dent Assoc. 2012;40(9):739-747.

76. Merrill RL, Graff-Radford SB. Trigeminal neuralgia: how to rule out the wrong treatment. J Am Dent Assoc. 1992;123(2):63-68.

77. Lutz J, Linn J, Mehrkens JH, et al. Trigeminal neuralgia due to neurovascular compression: high-spatial-resolution diffusiontensor imaging reveals microstructural neural changes. Radiology. 2011;258(2):524-530.

78. Jannetta PJ. Arterial compression of the trigeminal nerve at the pons in patients with trigeminal neuralgia. J Neurosurg. 1967;26(1):Suppl: 159-162.

79. Bakshi R, Lerner A, Fritz JV, Sambuchi GD. Vascular compression in trigeminal neuralgia shown by magnetic resonance imaging and magnetic resonance angiography image registration. Arch Neurol. 2001;58(8):1290-1291

80. Matsuka Y, Fort ET, Merrill RL. Trigeminal neuralgia due to an acoustic neuroma in the cerebellopontine angle. J Orofac Pain. 2000;14(2):147-151.

81. Feinerman DM, Goldberg MH. Acoustic neuroma appearing as trigeminal neuralgia. J Am Dent Assoc. 1994;125(8):1122-1125.

82. Jensen TS, Rasmussen P, Reske-Nielsen E. Association of trigeminal neuralgia with multiple sclerosis: clinical and pathological features. Acta Neurol Scand. 1982;65(3):182-189.

83. Fromm GH, Terrence CF, Chattha AS. Baclofen in the treatment of trigeminal neuralgia: Double-blind study and long-term follow-up. Ann Neurol. 1984;15(3):240-244.

84. Zakrzewska JM, Chaudhry Z, Nurmikko TJ, Patton DW, Mullens EL. Lamotrigine (lamictal) in refractory trigeminal neuralgia: results from a double-blind placebo controlled crossover trial. Pain. 1997;73(2):223-230.

85. Obermann M. Treatment options in trigeminal neuralgia. Ther Adv Neurol Disord. 2010;3(2):107-115.

86. Singh PM, Kaur M, Trikha A. An uncommonly common: glossopharyngeal neuralgia. Ann Indian Acad Neurol. 2013;16(1):1-8.

87. [No authors listed]. Classification of chronic pain. Descriptions of chronic pain syndromes and definitions of pain terms. Prepared by the International Association for the Study of Pain, Subcommittee on Taxonomy. Pain Suppl. 1986;3:S1-S226.

88. Marks PV, Purchas SH. Life-threatening glossopharyngeal neuralgia. Aust N Z J Surg. 1992;62(8):660-661.

89. Katusic S, Williams DB, Beard CM, Bergstralh EJ, Kurland LT. Epidemiology and clinical features of idiopathic trigeminal neuralgia and glossopharyngeal neuralgia: similarities and differences, Rochester, Minnesota, 1945-1984. Neuroepidemiology. 1991;10(5-6): 276-281.

90. Olds MJ, Woods CI, Winfield JA. Microvascular decompression in glossopharyngeal neuralgia. Am J Otol. 1995;16(3):326-330.

91. Merrill RL. Head and neck pain. Seminars in Anesthesia, Perioperative Medicine, and Pain. 1997;16(4):280-291.

92. Mathews GJOJ. Painful traumatic neuroma. Surg Clin North Am. 1972;52(5):1313-1324

93. Lee EJ, Calcaterra TC, Zuckerbraun L. Traumatic neuromas of the head and neck. Ear Nose Throat J. 1998;77(8):670-674, 676.

94. Derry S, Sven-Rice A, Cole P, Tan T, Moore RA. Topical capsaicin (high concentration) for chronic neuropathic pain in adults. Cochrane Database Syst Rev. 2013;2:CD007393.

95. Anand P, Bley K. Topical capsaicin for pain management: therapeutic potential and mechanisms of action of the new high-concentration capsaicin 8\% patch. Br J Anaesth. 2011;107(4):490-502.
96. H D, Wellish M, Gilden D. Topical ketamine treatment of postherpetic neuralgia. Neurology. 2003;60(8):1391.

97. Latremoliere A, Woolf CJ. Central sensitization: a generator of pain hypersensitivity by central neural plasticity. J Pain. 2009; 10(9):895.

98. Merrill RL. Orofacial pain mechanisms and their clinical application. Dent Clin North Am. 1997;41(2):167-188.

99. Headache Classification Committee of the International Headache Society (IHS). The International Classification of Headache Disorders. 3rd ed (beta version). Cephalalgia. 2013;33(9):629-808.

100. Peñarrocha M, Bandrés A, Peñarrocha M, Bagán JV. Lower-half facial migraine: a report of 11 cases. J Oral Maxillofac Surg. 2004;62(12): 1453-1456.

101. Daudia AT, Jones NS. Facial migraine in a rhinological setting. Clin Otolaryngol Allied Sci. 2002;27(6):521-525.

102. Stewart WF, Ricci JA, Chee E, Morganstein D. Lost productive work time costs from health conditions in the United States: results from the American Productivity Audit. J Occup Environ Med. 2003;45(12): 1234-1246.

103. Akerman S, Holland PR, Goadsby PJ. Diencephalic and brainstem mechanisms in migraine. Nat Rev Neurosci. 2011;12(10):570-584.

104. May A, Goadsby PJ. The trigeminovascular system in humans: pathophysiologic implications for primary headache syndromes of the neural influences on the cerebral circulation. J Cereb Blood Flow Metab. 1999;19(2):115-127.

105. McNaughton FL, Feindel W. Innervation of intracranial structures: a reappraisal. In: Rose FC, ed. Physiological aspects of clinical neurology. Oxford: Blackwell Scientific, 1977:279-293.

106. Andreou AP, Summ O, Charbit AR, Romero-Reyes M, Goadsby PJ. Animal models of headache: from bedside to bench and back to bedside. Expert Rev Neurother. 2010;10(3):389-411.

107. Bartsch T, Goadsby PJ. The trigeminocervical complex and migraine: current concepts and synthesis. Curr Pain Headache Rep. 2003;7(5):371-376.

108. Goadsby PJ, Lipton RB, Ferrari MD. Migraine - current understanding and treatment. $N$ Engl J Med. 2002;346(4):257-270.

109. Goadsby PJ, Edvinsson L, Ekman R. Vasoactive peptide release in the extracerebral circulation of humans during migraine headache. Ann Neurol. 1990;28(2):183-187.

110. Goadsby PJ. Migraine, allodynia, sensitisation and all of that .... Eur Neurol. 2005;53 Suppl 1:10-16.

111. Burstein R, Levy D, Jakubowski M. Effects of sensitization of trigeminovascular neurons to triptan therapy during migraine. Rev Neurol (Paris). 2005;161(6-7):658-660.

112. Durham PL. Calcitonin gene-related peptide (CGRP) and migraine. Headache. 2006;46 Suppl 1:S3-S8.

113. Oshinsky ML. Insights from experimental studies into allodynia and its treatment. Curr Pain Headache Rep. 2006;10(3):225-230.

114. Obermann M, Mueller D, Yoon MS, Pageler L, Diener H, Katsarava Z. Migraine with isolated facial pain: a diagnostic challenge. Cephalalgia. 2007;27(11):1278-1282.

115. Silberstein SD, Lipton RB, Dalessio DJ, eds. Wolff's Headache And Other Head Pain. 7th ed. New York: Oxford University Press; 2001:478-479.

116. Benoliel R, Elishoov H, Sharav Y. Orofacial pain with vasculartype features. Oral Surg Oral Med Oral Pathol Oral Radiol Endod. 1997;84(5):506-512.

117. Bernstein C, Burstein R. Sensitization of the trigeminovascular pathway: perspective and implications to migraine pathophysiology. J Clin Neurol. 2012;8(2):89-99.

118. Nicholson R, Buse DC, Andrasik F, Lipton RB. Nonpharmacologic treatments for migraine and tension-type headache: how to choose and when to use. Curr Treat Options Neurol. 2011;13(1):28-40.

119. Pistoia F, Sacco S, Carolei A. Behavioral therapy for chronic migraine. Curr Pain Headache Rep. 2012;17(1):1-8.

120. Akerman S, Romero-Reyes M. Insights into the pharmacological targeting of the trigeminocervical complex in the context of treatments of migraine. Expert Rev Neurother. 2013;13(9):1041-1059. 
121. Holland S, Silberstein SD, Freitag F, Dodick DW, Argoff C, Ashman E; Quality Standards Subcommittee of the American Academy of Neurology and the American Headache Society. Evidence-based guideline update: NSAIDs and other complementary treatments for episodic migraine prevention in adults: Report of the Quality Standards Subcommittee of the American Academy of Neurology and the American Headache Society. Neurology. 2012;78(17):1346-1353.

122. Silberstein S, Kori S. Dihydroergotamine: a review of formulation approaches for the acute treatment of migraine. CNS Drugs. 2013;27(5):385-394.

123. Sprenger T, Goadsby P. Migraine pathogenesis and state of pharmacological treatment options. BMC Med. 2009;7:71.

124. Buzzi MG, Moskowitz MA. Evidence for 5-HT1B/1D receptors mediating the antimigraine effect of sumatriptan and dihydroergotamine. Cephalalgia. 1991;11(4):165-168.

125. Rapoport A, Winner P. Nasal delivery of antimigraine drugs: clinical rationale and evidence base. Headache. 2006;46:S192-S201.

126. Carleton SC, Shesser RF, Pietrzak MP, et al. Double-blind, multicenter trial to compare the efficacy of intramuscular dihydroergotamine plus hydroxyzine versus intramuscular meperidine plus hydroxyzine for the emergency department treatment of acute migraine headache. Ann Emerg Med. 1998;32(2):129-138.

127. [No authors listed]. Treatment of migraine attacks with sumatriptan. The Subcutaneous Sumatriptan International Study Group. N Engl J Med. 1991;325(5):316-321.

128. Humphrey PP, Feniuk W. Mode of action of the anti-migraine drug sumatriptan. Trends Pharmacol Sci. 1991;12(12):444-446.

129. Shields KG, Goadsby PJ. Serotonin receptors modulate trigeminovascular responses in ventroposteromedial nucleus of thalamus: a migraine target? Neurobiol Dis. 2006;23(3):491-501.

130. Ma QP. Co-localization of $5-\mathrm{HT}(1 \mathrm{~B} / 1 \mathrm{D} / 1 \mathrm{~F})$ receptors and glutamate in trigeminal ganglia in rats. Neuroreport. 2001;12(8):1589-1591.

131. Ma QP, Hill R, Sirinathsinghji D. Colocalization of CGRP with 5-HT1B/1D receptors and substance $P$ in trigeminal ganglion neurons in rats. Eur J Neurosci. 2001;13(11):2099-2104.

132. Smith D, Shaw D, Hopkins R, et al. Development and characterisation of human 5-HT1B- or 5-HT1D-receptor specific antibodies as unique research tools. J Neurosci Methods. 1998;80(2):155-161.

133. Longmore J, Shaw D, Smith D, et al. Differential distribution of 5HT1D- and 5HT1B-immunoreactivity within the human trigeminocerebrovascular system: implications for the discovery of new antimigraine drugs. Cephalalgia. 1997;17(8):833-842.

134. Smith D, Hill RG, Edvinsson L, Longmore J. An immunocytochemical investigation of human trigeminal nucleus caudalis: CGRP, substance $P$ and 5-HT1D-receptor immunoreactivities are expressed by trigeminal sensory fibres. Cephalalgia. 2002;22(6):424-431.

135. Castro ME, Pascual J, Romón T, del Arco C, del Olmo E, Pazos A. Differential distribution of $[3 \mathrm{H}]$ sumatriptan binding sites (5-HT1B, 5-HT1D and 5-HT1F receptors) in human brain: focus on brainstem and spinal cord. Neuropharmacology. 1997;36(4-5):535-542.

136. Levy D, Jakubowski M, Burstein R. Disruption of communication between peripheral and central trigeminovascular neurons mediates the antimigraine action of $5 \mathrm{HT} 1 \mathrm{~B} / 1 \mathrm{D}$ receptor agonists. Proc Natl Acad Sci U S A. 2004;101(12):4274-4279.

137. Burstein R, Jakubowski M. Analgesic triptan action in an animal model of intracranial pain: a race against the development of central sensitization. Ann Neurol. 2004;55(1):27-36.

138. Smith TR, Sunshine A, Stark SR, Littlefield DE, Spruill SE, Alexander WJ. Sumatriptan and naproxen sodium for the acute treatment of migraine. Headache. 2005;45(8):983-991.

139. Mathew NT, Landy S, Stark S, et al. Fixed-dose sumatriptan and naproxen in poor responders to triptans with a short half-life. Headache. 2009;49(7):971-982.

140. Dodick D, Lipton RB, Martin V, et al; Triptan Cardiovascular Safety Expert Panel. Consensus statement: cardiovascular safety profile of triptans (5-HT agonists) in the acute treatment of migraine. Headache. 2004;44(5):414-425.
141. Ho T, Ferrari M, Dodick D, et al. Efficacy and tolerability of MK-0974 (telcagepant), a new oral antagonist of calcitonin gene-related peptide receptor, compared with zolmitriptan for acute migraine: a randomised, placebocontrolled, parallel-treatment trial. Lancet. 2008;372:2115-2123.

142. Färkkilä M, Diener HC, Géraud G, et al. Efficacy and tolerability of lasmiditan, an oral 5-HT $(1 \mathrm{~F})$ receptor agonist, for the acute treatment of migraine: a phase 2 randomised, placebo-controlled, parallel-group, dose-ranging study. Lancet Neurol. 2012;11(5):405-413.

143. Ferrari MD, Färkkilä M, Reuter U, et al; European COL-144 Investigators. Acute treatment of migraine with the selective 5-HT1F receptor agonist lasmiditan - a randomised proof-of-concept trial. Cephalalgia. 2010;30(10):1170-1178.

144. Lance JW, Goadsby PJ. Mechanism and Management of Headache. 7th ed. Philadelphia, PA: Elsevier Butterworth Heinemann; 2005.

145. Gady J, Ferneini EM. Botulinum toxin A and headache treatment. Conn Med. 2013;77(3):165-166.

146. Mathew NT, Frishberg BM, Gawel M, Dimitrova R, Gibson J, Turkel C; BOTOX CDH Study Group. Botulinum toxin type A (BOTOX) for the prophylactic treatment of chronic daily headache: a randomized, double-blind, placebo-controlled trial. Headache. 2005;45(4):293-307.

147. Aurora SK, Gawel M, Brandes JL, Pokta S, Vandenburgh AM; BOTOX North American Episodic Migraine Study Group. Botulinum toxin type a prophylactic treatment of episodic migraine: a randomized, double-blind, placebo-controlled exploratory study. Headache. 2007;47(4):486-499.

148. Dodick DW, Turkel CC, DeGryse RE, et al; PREEMPT Chronic Migraine Study Group. Onabotulinumtoxin A for treatment of chronic migraine: pooled results from the double-blind, randomized, placebocontrolled phases of the PREEMPT clinical program. Headache. 2010;50(6):921-936.

149. Mueller O, Diener HC, Dammann P, et al. Occipital nerve stimulation for intractable chronic cluster headache or migraine: a critical analysis of direct treatment costs and complications. Cephalalgia. Epub June 28, 2013.

150. Silberstein SD, Dodick DW, Saper J, et al. Safety and efficacy of peripheral nerve stimulation of the occipital nerves for the management of chronic migraine: results from a randomized, multicenter, doubleblinded, controlled study. Cephalalgia. 2012;32(16):1165-1179.

151. Schurks M, Diener HC, Goadsby P. Update on the prophylaxis of migraine. Curr Treat Options Neurol. 2008;10(1):20-29.

152. Rasmussen BK. Migraine and tension-type headache in a general population: precipitating factors, female hormones, sleep pattern and relation to lifestyle. Pain. 1993;53(1):65-72.

153. Olesen J. Clinical and pathophysiological observations in migraine and tension-type headache explained by integration of vascular, supraspinal and myofascial inputs. Pain. 1991;46(2):125-132.

154. Jensen R, Rasmussen BK, Pedersen B, Olesen J. Muscle tenderness and pressure pain thresholds in headache. A population study. Pain. 1993;52(2):193-199.

155. Bendtsen L, Fernández-de-la-Peñas C. The role of muscles in tensiontype headache. Curr Pain Headache Rep. 2011;15(6):451-458.

156. Fernández-de-Las-Peñas $\mathrm{C}$, Alonso-Blanco $\mathrm{C}$, Cuadrado $\mathrm{ML}$, Pareja JA. Myofascial trigger points in the suboccipital muscles in episodic tension-type headache. Man Ther. 2006;11(3):225-230.

157. Fernández-de-las-Peñas C, Alonso-Blanco C, Cuadrado ML, Gerwin RD, Pareja JA. Myofascial trigger points and their relationship to headache clinical parameters in chronic tension-type headache. Headache. 2006;46(8):1264-1272.

158. Kaniecki RG. Tension-type headache. Continuum (Minneap Minn). 2012;18(4):823-834.

159. Bendtsen L, Jensen R. Treating tension-type headache - an expert opinion. Expert Opin Pharmacother. 2011;12(7):1099-1109.

160. Bendtsen L, Evers S, Linde M, Mitsikostas DD, Sandrini G, Schoenen J; EFNS. EFNS guideline on the treatment of tension-type headache - report of an EFNS task force. Eur J Neurol. 2010;17(11): 1318-1325. 
161. Lipton RB, Bigal ME, Diamond M, Freitag F, Reed ML, Stewart WF Migraine prevalence, disease burden, and the need for preventive therapy. Neurology. 2007;68(5):343-349.

162. LeResche L. Epidemiology of temporomandibular disorders: implications for the investigation of etiologic factors. Crit Rev Oral Biol Med. 1997;8(3):291-305.

163. Mitrirattanakul S, Merrill RL. Headache impact in patients with orofacial pain. J Am Dent Assoc. 2006;137(9):1267-1274.

164. Gonçalves DA, Bigal ME, Jales LC, Camparis CM, Speciali JG. Headache and symptoms of temporomandibular disorder: an epidemiological study. Headache. 2010;50(2):231-241.
165. Franco AL, Gonçalves DA, Castanharo SM, Speciali JG, Bigal ME, Camparis CM. Migraine is the most prevalent primary headache in individuals with temporomandibular disorders. J Orofac Pain. 2010;24(3):287-292.

166. Goadsby PJ, Cohen AS, Matharu MS. Trigeminal autonomic cephalalgias: diagnosis and treatment. Curr Neurol Neurosci Rep. 2007;7(2):117-125.

167. Leone M, Bussone G. Pathophysiology of trigeminal autonomic cephalalgias. Lancet Neurol. 2009;8(8):755-764.

168. May A. Update on the diagnosis and management of trigeminoautonomic headaches. J Neurol. 2006;253(12):1525-1532.
Journal of Pain Research

\section{Publish your work in this journal}

The Journal of Pain Research is an international, peer-reviewed, open access, online journal that welcomes laboratory and clinical findings in the fields of pain research and the prevention and management of pain. Original research, reviews, symposium reports, hypothesis formation and commentaries are all considered for publication.

\section{Dovepress}

The manuscript management system is completely online and includes a very quick and fair peer-review system, which is all easy to use. Visit http://www.dovepress.com/testimonials.php to read real quotes from published authors.

\footnotetext{
Submit your manuscript here: http://www.dovepress.com/journal-of-pain-research-journal
} 